\title{
Organizational Change in Business Environment and the Main Barriers during Organizational Changes
}

\author{
Jeton Zogjani, M.Sc \\ zogjanijeton@gmail.com
}

Samed Raçi, M.Sc

samed.raci@gmail.com

Doi:10.5901/ajis.2015.v4n3p83

\begin{abstract}
In the business environment, the process of organizational change is the need of time, then this need is the result of dynamic and continuous development that have business environment in the domestic economy as well as the modern global economy. Managing the organizational changes is very important process for organizational leadership. On one hand, the leadership constantly aims that the process of planning and implementing changes in the business environment have to be more effective in organization while on the other side, employee resistance during organizational change and the cost of change in the organization have be as minimal. The main objectives in this paper are as following: which are two main barriers in organizational change? Which is the key efficiency of organizational change? What effect they can have on change and how they can manage? Which are the main approaches that businesses should prepare for organizational change? How is reasonable the Kurt Lewin's model in organizational change, etc. In this research paper are identify different barriers that can appears during process of organizational change in business environment, such as: the first is power and in general the power is characterised as key elements in managerial achievement and as a main source of managerial efficiency in organizational change, then as similar barrier within the organisation change can be social force, it aims to use their social influence to stop or delay changes that affect them negatively in their interest; the second is described as mismanaging change models and approaches in modern business environment and some evidence shown that $60 \%$ of reported projects in organization change have failed, then theorists have argued that this model of change in business environment are inadequate in the current economy.
\end{abstract}

Keywords: fundamental change, human relationships, Lewin's model, motivation, organizational leadership.

\section{Introduction}

In first part of research paper is analyzed the impact of organizational change in business environment and in second part are identified the main barriers that may appear during organizational changes processes. Different research papers have shown that the process of change is very dynamic process and the dynamic processes repeatedly challenges business environment. In business environment with dynamic processes is the most important to have their ability and to manage these changes as well as possible, particularly in modern economy where the process of organizational change is as a routine process. Process of organizational change involves some factors that are very important during the process of change, such as: type of (organizational) change, the process of changing factors, environmental factors and results of change, (Dergjini, 2011). Organizational changes can be as barriers in business environment and it can be mostly when the businesses do not have enough abilities to respond the organizational changes. In our research paper are identified the main barriers during the organizational change, they are: (social) power, mismanaging change models and approaches. But, different sources and authors have summarized these barriers in process of organizational change, such as: negative employee attitudes, organizational culture and unproductive management behaviour. Regardless, these barriers the process of organizational changes in the business environment is unstoppable, then in process of organizational change is very important to be positive, acceptable and appropriate for all groups that are involved in the process of change. 


\section{Literature Review}

The need to successfully change within businesses has been argued by many theorists as being a difficult task (Kanter et al. 1992). With it follows a view that most businesses should view organisational change as a core competency (Burnes, 2005). In the current economical environment, most businesses are still recovering or have recovered from the recent recession. It is important that all understand what is key in order to effectively change efficiently and quickly, overcoming the barriers and resistance to change as smoothly and professionally as possible, as to not damage a business further. The following research paper looks at two barriers to change which can affect a business if left unchecked, and can delay or negatively alter the course of organisational change. Throughout, the two barriers are identified to why they are a barrier to change, what effect they have on the business and are analysed to how they can be managed.

The first barrier to change that is contained within the internal segment of a business is power. 'Power is generally regarded as the key to managerial achievement, if only in enabling users to get things done. Posits powerlessness as a major source of managerial inefficiency, resulting in wasted time, needless conflict, stress, anger and frustration.' (Drummond, 1992). Power can come in many forms, from power that is naturally acquired, by being in a position within the business with decision making abilities, such as company director. To informal forms of power, acquired socially. 'Power in the social world can be a term given to a facet, or facets, of human relationships, and hence discussed with regard to relationships between people. Alternatively, power can be seen as a personal trait, or power can be viewed as a consequence of position within in a hierarchy.' (Horton, 2003)

Social powers can be barriers to change, whereby people within the organisation use their social influence to stop or delay changes that affect them negatively. Weber (1978) describes social power as, 'the ability of a person to influence others and make them do things they would not do otherwise'. Robin (1992) discusses that there is a 'procession' perspective on power. He says that, 'Power is seen as lying not in concrete resources but in strategies like coalitionformation and the manipulation of information'. A perspective like this can usually be seen from a social perspective from within a social circle, whereby power such as experience or knowledge is grouped instead of internal power such as hierarchy. This can usually effect change when power is going to be removed from one of a social group. An example of where a large amount of power would be within an organisation would rest, is within the role of managers, who as French and Raven (1959) note have the five, Reward, Coercive, Legitimate, References and Expert powers.

Problems occur when the need for change would force a manager's position redundant, causing an abuse or misuse their powers. This can come from a managers assumption of the perceived organisational support (Zagenczyk et Al, 2010), and when removed can cause a loss of parochial (self interest) benefits gained from the power provided. Kipnis (1972) states that, 'People who have power think and act differently from people who lack it'. With that said, managers can manipulate change so that it can benefit their situation instead of adjusting with change. For example, mangers can use their social influence (Burt, 1987) with people on their own level, such as managers in other departments, to group together to oppose decisions that will affect the social group. (Lorrain \& White, 1971) quotes that, 'employees are said to be structurally equivalent to the extent that they share the same relationships with the same set of other people in the organization regardless of whether they are connected themselves'.

They can also abuse the position they are in order to alter the message of change as it is passed down through each communication channel. This can be achieved by 'Gaming emotions' (Eduardo Et Al, 2009) in order to fake emotions, and make subordinates think the change is negative, or by not passing on the message at all, thereby not having the full support of the whole organisation when trying to alter the direction of the business. This is supported by Allen et Al (2007), whose case study on the quality of information shows that the quality of information given to employees reported having a clearer understanding of the change, and an increased support for most change. Kotter (1990) can support this argument with his emphasis into the importance of communication in change processes, and likewise Liao (2008) quotes that 'Knowledge has become the most precious property of company'.

In order to remove or alter this barrier to change, a simple solution would be to remove the problematic segments of the business, thus removing the social powers and allowing a clear message to flow through the business. However it will be hard for a business to identify where the problems areas are, unless they work at the same level with problematic managers and experience the problems first hand. So therefore, the use of empowering all employees in order to bypass problems such miscommunication can be done. Empowering has also been described as being given personal power (Galinsky, et Al 2008; Van Dijke \& Poppe, 2006). The use of personal powers has been associated with the idea that, People who experience a substantial amount of personal power are unconstrained by, and independent from, others (Cartwright, 1959; Emerson, 1962), freeing them from powers managers currently hold such as Legitimate and Coercive powers. This is backed up with empirical research that associates the use of transformational leadership and an 
employee's willingness to support organisational change (Bommer et al 2005). Although it comes at a cost of time and effort, it can effectively remove any problems in communication and motivation for the business and its objectives (Gilgeous, 1997).

The use of a company intranet, whereby employees can be made aware of change through updates can be used to promote business change. However problems such as employees not checking or misunderstanding the updates or news about change will also have the adverse effect, by creating a barrier of the uncertainty towards the change (Begley, 1998).Theorists also comment that empowerment will be difficult to promote (Eccles, 1993; Lee, 1999; Stohl and Cheney, 2001), and therefore may be tough to implement within all businesses as it will take power away from other areas. Therefore empowerment must be managed and implemented effectively and when necessary, as empowering the wrong people in the wrong business environment may damage the business structure.

A further barrier to change is that companies are mismanaging change models and approaches, as it is currently stated that $60 \%$ of reported change projects fail (Burnes 2004; B). Change theories such as Lewin's planned change and three part model (Lewin, 1947), developed years ago have been criticised as being outdated, (Burnes 2004; A). Theorists argue that approaches such Lewin's are unsuitable in the current economy (Stacey, 1996; Styhre, 2002), while approaches such as the emergent approach is a much more effective way to plan for change (Burnes, 2009). In a modern economical environment, communication plays a much more important role then when the most widely influential change models such as Lewin's were created. Tanyel and Mitchell (1999) report a litany of communication abilities expected by employers, including 'written communication, oral communication, leadership communication, team skills, presentation skills, global/cultural awareness, and interpersonal communication'. The need for increased skills in efficient communication with both the internal and external environment (Wardrope et Al, 1999) means the need to freeze in Lewin's 3 part change in order to implement change is unacceptable if a business wishes to change effectively while still operating at maximum potential.

By the same respect, emergent and complexity approaches have had a number of criticisms in its approaches to prepare businesses for change and the steps necessary. Theorists such as Wheatley (1992) have compared complexity approaches to states where, 'the laws of cause and effect appear not to apply', whereby businesses develop into a stage of 'self-organisation governed by a small group of individuals' (Burnes 2004; A). The criticisms come from that in order for these approaches to come into effect a business must operate, ' on the edge of chaos' (Brown and Eisenhardt, 1997), where there, businesses either effectively manage change through self management, or, 'fall over the edge'. A difficulty faced with any change is that during the transition between changes is that any vision or reasoning behind the change may have altered. For example if a business is going through a serious change to keep up with a market leader technologically, or innovatively. A business may struggle to keep its market share and competitiveness, especially in the consumer market. Burnes (2004; A) backs this up by citing Brown and Eisenhardt's (1997), research into computer says that, 'that continuous innovation is necessary for survival and that this is brought about by a process that resembles selforganization in nature.'. And therefore if a slowed placed change approach such as Lewin's three steps is implemented within the wrong market or business environment, a business may fall behind competitively, or it may just be an ineffective approach to change.

A further difficulty would be that, while it is easier to rapidly change the structure of an organisation, it is a much harder and slower process to change a business's culture (Allaire and Firsirotu, 1984; Handy, 1993). Therefore in a fast paced organisation, it will become paramount for a business to be able to prioritise and maintain the slow alteration of culture, whilst simultaneous rapidly changing its structure, making the decision into which approach to take a difficult one. In order for organisations to overcome this problem they must analyse the problems they might face as a company and use the appropriate models and approaches to aid them. However this cannot always be that simple, as Tsoukas and Chia (2002) note that not all change is expected. An example would be how banks rapidly responding to the recession and financial problems by releasing unique offers and aid to ensure customers stayed loyal to them (ABA Bank Marketing, 2009).

Looking at Medley et al (2008), she describes how Lewin's model would aid businesses that operate in community/non-profit organisations. It details how a non profit organisation can adapt Lewin's three part model and combines it with areas such as strategic planning in order to redefine missions and programmes to engage in successful organisational change.

Following this, it can be fair to say that for businesses that have the time to plan change and are aware of the difficulties in ahead of them, an approach such as Lewin's where time can be taken to stop the process, is acceptable, this is backed up by Medley (2008) addressing that, Lewin's work is 'advantageous in building a more robust process'.

Likewise, as previously mentioned, in businesses that operate in the consumer retail market, where competition 
and innovation play a much more vital role (Brown and Eisenhardt, 1997), a need to adapt and change to situations such as staying competitive with a market leader in innovation or quality is paramount, this may be down to businesses needing to be restructured or altered, and as such, an emergent approach may be more suitable. Therefore businesses that operate in these markets will have to be reactive instead of proactive, (Pettigrew, 2000) 'Emergent change consists of ongoing accommodations, adaptations, and alterations that produce fundamental change without a priori intentions to do so'. Therefore in order for businesses to fully utilise the correct change model and approach for their business, they must first look into where change will occur for their business, and whether they can afford the time to use a planned approach to change, or have to be adaptive and alter while still operating, in an emergent approach to change.

\section{Methodology}

This research paper aims to evaluate the impact of organizational change in business environment and to indentify the main barriers during processes of organizational change. From previous discussions around topic is evident that research implementation (enforcement) method can used to analyze organizational change and their barriers. As argue (Jakupi 2005), this method is supported in theoretical works and through this method we aims to gain new knowledge and guidance that have resolution of any specific task, namely the solution of practical problems (such as: in the processes of organizational change). Most of sources that are used in research papers are related to the issue of the topic and are collected by different sources, such as: journal papers, different books of authors and reports from institutions. However, this research method is more appropriate for this kind of research.

\section{Conclusion}

In conclusion, both barriers have different variables in which the barrier to change is created. For power, the barrier can reside within lower level employees in the hierarchy such as managers and their subordinates. Whereas the mismanagement of approaches comes in the decision making, with problems in leadership, direction and knowledge of change models/theories and what each approach entail. The need to deal with barriers to change may not always have to be negative, such as the empowerment of employees, may be seen to some as a positive effect towards change, thus removing the barriers. A business must always identify and deal with the barriers to change according and differently, depending on the barrier in question, or the problem it's causing. Regardless, as both barriers mentioned, for change to become effective in any environment or business, it is vital that the organisation focus and support the change as a whole and positively, and where possible remove or adjust around any barriers found during the process.

\section{References}

ABA Bank Marketing (2009), Banks Respond to Recession with Unique Offers, Education to Aid Customers. 41 (6)

Allaire, Y. \& Firsirotu, M.E. (1984), Theories of organizational culture, Organization Studies, 5 (3), pp. 193 - 226

Allen, J; Jimmieson N; Bordia P; Irmer B, (2007), Uncertainty during Organizational Change: Managing Perceptions through Communication, Journal of Change Management, 7 (2), pp. 187 - 210

Begley, T. M. (1998). Coping strategies as predictors of employee distress and turnover after an organizational consolidation: a longitudinal analysis, Journal of Occupational and Organizational Psychology, 71 (4), pp. 305 - 330

Bommer, W; Gregory, R; Robert, R (2005), Changing attitudes about change: Iongitudinal effects of transformational leader behaviour on employee cynicism about organizational change. Journal of Organizational Behaviour, 26 (7), pp. 733 - 753

Brown, S.L. \& Eisenhardt, K.M. (1997). The art of continuous change: linking complexity theory and time-paced evolution in relentlessly shifting organizations. Administrative Science Quarterly, 42 (1), pp. 1 - 34

Burnes, B. (2004/a). Kurt Lewin and complexity theories: back to the future? Journal of Change Management, 4 (4), pp. 309 - 325

Burnes, B. (2004/b). Emergent Change and Planned Change - Competitors or Allies. International Journal of Operations and Production Management, 24 (9), pp. 886 - 902

Burnes, B. (2005). Complexity theories and organizational change International Journal of Management Reviews, 7 (2), pp. 73 - 90

Burnes, B. (2009/a). Managing Change, 5th ed. (Harlow, FT: Prentice Hall).

Burt, R. S. (1987). Social contagion and innovation: Cohesion versus structural equivalence. American Journal of Sociology, 92 (6), pp. $1287-1335$.

Cartwright, D. (1959). A field theoretical conception of power. Studies in social power, (pp. 183 - 220), Ann Arbor: University of Michigan

Dergjini, A. (2011). Managing change in business organization in Albania: factors that reflect in success of change. University of Tirana, Albania

Drummond, H. (1992). Auditing your personal power, Management development review. 5 (2)

Eccles, T. (1993). 'The deceptive allure of empowerment', Long Range Planning, 26 (6), pp. 13 - 21 
Eduardo, A \& Teck-Hua, H. (2009), Gaming Emotions in Social Interactions. Journal of Consumer Research, 36 (4), pp. 539 - 552

Emerson, R.M. (1962). Power dependence relations. American Journal of Sociology, 27 (1), pp. 31 - 41

French, J. \& Raven, B.H. (1959). The Bases of Social Power. Studies in Social Power, Ann Arbor, MI: Institute for Social Research.

Galinsky, A.D., Magee, J.C., Gruenfeld, D.H., Whitson, J., \& Liljenquist, K.A. (2008). Social power reduces the strength of the situation: Implications for creativity, conformity, and dissonance. Journal of Personality and Social Psychology, 95 (6), pp. 1450 - 1466

Gilgeous, V (1997). Operations and the management of change. London: Pitman Publishing

Handy, C. (1993). Understanding Organizations. 4th ed. Penguin, Harmondsworth.

Horton, K (2003). Strategy, practise and the dynamics of power. Journal of business Research. 56 (2)

Jakupi, A. (2005). Research methodology: authorized lecture, Faculty of Economics, University of Pristine (Kosovo).

Kanter, R.M., Stein, B.A. \& Jick, T.D. (1992). The Challenge of Organizational Change. New York: Free Press

Kipnis, D. (1972). Does power corrupt? Journal of Personality and Social Psychology, 24 (1), pp. 33 - 41

Kotter, J.P. (1990), A Force for Change: How Leadership Differs from Management, The Free Press, New York, NY.

Lee, M. (1999). The lie of power: empowerment as impotence'. Human Relations, 52 (2), pp. 225 - 262

Lewin, K. (1947). 'Frontiers in group dynamics', in: D. Cartwright (Ed.) (1952): Field Theory in social Science. Social Science Paperbacks: London.

Liao, L (2008), Knowledge-sharing in R\&D departments: a social power and social exchange theory perspective. International Journal of Human Resource Management, 19 (10), pp. 1881 - 1895

Lorrain, F. \& White, H. C. (1971). Structural equivalence of individuals in social networks, Journal of Mathematical Sociology, 1 , pp. 49 80

Medley, B \& Akan, O., (2008). Creating positive change in community organizations: A case for rediscovering Lewin, Nonprofits Management \& Leadership, 18 (4), pp. 485 - 496

Pettigrew, A. M. (2000) "Linking Change Processes and Outcomes: A Commentary on Ghosal, Bartlett and Weick." In M. Beer and N. Nohna (eds.), Breaking the Code of Change, Boston: Harvard Business School Press

Robin, F (1992), Perspectives on Power: Procession, Institutional and 'Internal' Forms of Organizational Power. Journal of Management Studies, 29 (6), pp. $741-759$

Stacey, R.D. (1996) Strategic Management and Organisational Dynamics, 2nd Edition, Pitman, London

Stohl, C. and Cheney, G. (2001) Participatory Processes/Paradoxical Practices, Management Communication Quarterly, 14 (3), pp. 349 - 407

Styhre, A. (2002). Non-linear change in organizations: organization change management informed by complexity theory. Leadership and Organization Development Journal, 23 (6), pp. 343 - 51

Tanyel, F, \& Mitchell, M, (1999). The skill set for success of new business school graduates: Do perspective employers and university faculty agree? Journal of Education for Business, 75, pp. 33 - 38

Tsoukas, H. and Chia, R. (2002). On organizational becoming: rethinking organizational change, Organization Science, 13 (5), pp. 567 583

Van Dijke, M., \& Poppe, M. (2006). Striving for personal power as a basis for social power dynamics, European Journal of Social Psychology, 36 (4), pp. 537 - 556

Wardrope, W; Bayless, M (1999), Content of the Business Communication Course: An Analysis of Coverage, Business Communication Quarterly, 62 (4), pp. 33 - 40

Weber, M. (1978). Economy and society. Berkeley: University of California Press. (Original work published 1914)

Wheatley, M.J. (1992) Leadership and the New Science: Learning about Organization from an Orderly Vnvierse, San Francisco, CA: Barrett-Koehler

Zagenczyk, T; Scott, K; Gibney, R; Murrell, A; Thatcher, J, (2010), Social influence and perceived organizational support: A social networks analysis. Organizational Behaviour \& Human Decision Processes, 111 (2), pp. 127 - 138 
